\title{
Birth preparation acupuncture for normalising birth: An analysis of NHS service routine data and proof of concept
}

\author{
Lokugamage AU, Eftime VAI, Porter D, Ahillan T, Ke SX.
}

\begin{abstract}
A number of studies show that acupuncture may help with labour and delivery. An NHS maternity acupuncture service providing birth preparation acupuncture has assessed its routine hospital maternity annual data from 2014 to 2016 to see what effect it had on labour and delivery outcomes. Data from this service was analysed and women who had birth preparation acupuncture were compared with those who did not receive it. Maternal age, parity and socio-economic status were considered confounders and were adjusted for in the analysis. Women who received acupuncture had more normal births (less surgical births) [OR 0.76 $(0.64,0.91)]$ required less intrapartum analgesia [OR $0.74(0.63,0.86)]$, less components of induction of labour [OR $0.74(0.61,0.91)]$ and reduced length of hospital stay [OR $0.91(0.87,0.95)]$. Patients highly valued the availability of acupuncture within the maternity service as it enhanced their patient journey.
\end{abstract}

\section{Impact Statement}

What is already known on this subject?

Numerous studies provide evidence for the effects of acupuncture in normalising pregnancy and birth. These effects include musculoskeletal preparation of the pelvis, cervical ripening, enhancing endogenous oxytocin release, and analgesic properties.

\section{What do the results of this study add?}

Our analysis shows that women who received birth preparation acupuncture had less surgical births, required less intrapartum analgesia, less components of induction of 
labour and reduced length of hospital stay, supporting the use of maternity acupuncture in normalising birth outcomes.

What are the implications of these findings for clinical practice and/or further research? The findings show that acupuncture, by potentially normalising birth, may potentially lead reductions to service costs. Further, additional research is required to see whether acupuncture is cost effective and could have an adjunctive role as a complementary therapy for improving birth outcomes and a woman's experience of childbirth.

\section{Introduction}

Acupuncture has been used historically in all areas of health to enhance physiology and physiological repair of illness (Plummer 1981). There is evidence to suggest that acupuncture is a safe intervention (Moon et al. 2019) that enhances emotional (Gould \& MacPherson 2001; Ormsby et al. 2017; Carvalho et al. 2013) and physical resilience (Watanabe et al. 2014). The postulated neurophysiological mechanisms involve the activation of several cortical areas and descending inhibitory pathways (Takeshige et al. 1992) as well as endogenous opioids (Zhao 2008).

Pre-existing research shows that acupuncture may be beneficial in the treatment of pelvic/back pain of pregnancy (Liddle \& Pennick 2015). There is also promising data on its use for labour analgesia and some very small studies suggesting a reduction in the length of labour (Chang et al. 2004; Mucuk \& Baser 2014; Smith et al. 2011; Rabl et al. 2001). Acupuncture is known to promote homeostasis so using it for induction of labour i.e. stimulating a uterus into labour when it is not physiologically ready is counterintuitive. However, evidence from the 2017 Cochrane review indicates that 
acupuncture could contribute by promoting cervical ripening (Smith et al. 2017). In animal studies, this effect may equal the performance of prostaglandins (Gribel et al. 2011). Moreover, there is evidence that acupuncture-type interventions influence optimal fetal positions such as the resolution of the breech presentation (van den Berg et al. 2008; Li et al. 2009).

The Whittington Hospital (London, UK) has a Maternity Acupuncture Service run in partnership with the Asante Academy of Chinese Medicine; this project offers a nonpharmacological approach which aims to enhance pregnancy-related physical and emotional health. The service offers birth preparation acupuncture on a weekly basis in the last trimester of pregnancy. Historically, Traditional Chinese acupuncture for birth preparation postulates (on an empirical basis) improved birth outcomes (Duke \& Don 2005).

There is a need to investigate methods of birth preparation and improve birth physiology to counterbalance the progressive rise in obstetric and potential offspring iatrogenic morbidity related to the increase of caesareans (Dominguez-Bello et al. 2016, Einarsdóttir et al. 2013; Higgins et al. 2013; Mesquita et al. 2013; Solheim et al. 2011; Vogel et al. 2015; Feng et al. 2014).

Giving birth is a complex bio-psycho-social process, where continuous emotional support and home-like birth settings help (Birthplace in England Collaborative Group 2011; DeJonge et al. 2015; Hodnett et al. 2013). However, acupuncture could influence the psychobiological pathways possibly mediated via endogenous oxytocin mechanisms (Lokugamage 2013; Taylor et al. 2000). Physiological studies involving acupuncture have been seen to increase oxytocin levels (Uvnäs-Moberg et al. 1993; Zhang et al. 
2012) and serotonergic mechanisms (Moazzami et al. 2010). There is scope within maternity care systems for improved emotional support for parents in the birth arena as well as improved preparation of the musculoskeletal structures of the body for childbirth (Liddle \& Pennick 2015).

We are aware that there is a limited but increasing amount of evidence for the use of acupuncture in women's health. However, this is not at odds with the general evidence levels behind guidelines in obstetrics and gynaecology. Three separate analyses of guidelines in the UK, USA and Canada (RCOG, ACOG and SOGC) demonstrate that they are underpinned by low levels of (grade A) high quality scientific data. Most recommendations are empirical and based on best practice opinion (Ghui et al 2016; Prusova et al. 2014; Wright et al. 2011).

In standard obstetrics textbooks (Murphy 2017) the factors that influence the success of vaginal birth are the 'Power, Passage and the Passenger' otherwise known as the '3P's' (Lokugamage 2016). It may also possible to add a 4th ' $\mathrm{P}$ ' involving the psychobiological status of the patient. Power relates to the propulsion of the baby through the birth canal and may be associated with female empowerment. Passage refers to the pelvic dimensions and muscles, which can be impaired by musculoskeletal pain. Passenger is associated with the size and presentation of the newborn. Acupuncture may influence all '4 Ps' at different stages during pregnancy (Table 1).

\section{Methods}

This paper was designed as an enhanced clinical audit with adjustment of typical confounders. We used NHS Health Research Authority (http://www.hra- 
decisiontools.org.uk) tool which deemed that ethics approval was not required for this analysis.

The Whittington maternity acupuncture service is a free NHS service and women are made aware of it through hospital staff, other patients and online information. Women self-refer to the service for birth preparation and receive weekly acupuncture sessions from 37 weeks gestation.

The acupuncturists were a team from the Asante Academy of Chinese Medicine, who were at that time part of the Middlesex University teaching structure for Traditional Chinese Medicine. Acupuncture point prescriptions were tailored according to Traditional Chinese Medicine principles.

Data was collected from over 6000 Whittington Maternity Service users between 2012 and 2014. The data were anonymised following an initial postcode analysis of deprivation. The main aim of the analysis was to compare birth outcomes between women who had received acupuncture during pregnancy and those who had not, taking into account their baseline characteristics. Routine electronic prospective data was collected for the maternity service audit purposes and also for information for service commissioners and the analysis is based on this observational cohort data from the hospital's maternity electronic database.

Additionally, service user experience data was collected through the form of an annual non-validated questionnaire collecting patient feedback on the Maternity Acupuncture service from 2014 to 2016. This questionnaire was offered over a two-month period every autumn to patients who have had 4 or more sessions in the clinic. This represents a sample of around $5-15 \%$ of the patient population, with both qualitative and 
quantitative data being collected to assess the quality of the patients' journey.

\section{Statistical Analysis}

The first set of analyses compared the demographics of women receiving and not receiving acupuncture, hoping to uncover potential confounders. The unpaired t-test was used to compare the age of the two groups, whilst the chi-square test was used to compare parity and deprivation of the two groups (Table 2).

The second and main set of analyses (Table 3) compared birth outcomes between the two groups. There were five outcome variables in the study. Two of these, induction and episiotomy were binary outcomes (yes or no). Another two outcomes were ordinal in nature. Pain relief was categorised as one of four categories, these being in order: none, gas/air, regional anaesthetic and general anaesthetic. Type of delivery was also considered an ordinal outcome, measured as one of three categories: normal vaginal delivery, use of instruments, and caesarean. The final outcome was postnatal length of stay. This variable had a positively skewed distribution and thus was given a logarithmic transformation before analysis.

All analysis was performed using regression methods. Logistic regression was used for the two binary outcomes, ordinal logistic regression was used for the ordinal outcomes, whilst linear regression was used for length of stay.

The difference between women receiving and not receiving acupuncture was examined in several analyses for each outcome. Firstly, the difference between groups was examined without factoring in any potentially confounding factors. Subsequently the differences were adjusted for various confounding factors. Adjustments were made, in turn, for age, parity and social deprivation for all outcomes. In addition, a further 
adjustment for induction was made for the delivery outcome, whilst both the episiotomy and length of stay outcomes were additionally adjusted for delivery type.

Additional analyses examined the effect of social deprivation upon the induction and delivery outcomes. The non-validated questionnaire data was reported without being subjected to further descriptive analysis (Table 4).

\section{Results}

\section{Birth preparation}

The first of analyses (Table 2) examined the differences between the two groups in terms of their demographics, and the results are summarised in Table 3. The figures presented for age are the mean and standard deviation, whilst for parity and deprivation the number and percentage in each group are reported. P-values indicating the statistical significance of the results are also reported. The results indicated that there were highly significant differences between women having and not having acupuncture for all three factors.

The mean age of women undergoing acupuncture was almost 34 , compared to a mean age of almost 31 for the group not undergoing acupuncture. Over $70 \%$ of women having acupuncture were having their first baby, compared to only half the non-acupuncture group. Over half of the acupuncture group came from the first two social quintiles.

Regression methods were used to examine the association of acupuncture upon various birth outcomes, and the results are summarised in Table 3. For the first four outcomes, the differences between acupuncture and non-acupuncture groups are reported in terms of odds ratios. For induction and episiotomy, these represent the odds of the outcome for women having acupuncture compared to those not having it. For pain relief and 
delivery, the odds ratios represent the odds of being in the next highest category with the use of acupuncture. For length of stay, the differences are presented in the form of ratios, indicating the length of stay in the acupuncture group relative to the length of stay for the non-acupuncture group. P-values to indicate the statistical significance of the results are also reported.

The results indicated that, once age, parity and deprivation and type of delivery (where appropriate) were adjusted for, there were significant differences between women who did and did not have acupuncture for all outcomes, with the exception of episiotomy (Table 3).

The results for pain relief indicated that there was no unadjusted difference between the two groups, or when age was accounted for. However, after factoring in parity, the difference was statistically significant. The odds of progressing to the next form of pain relief for women who had acupuncture were three-quarters of that of women who did not have acupuncture.

After adjusting for age and further confounding factors, there was a statistically significant difference. The odds of induction were three-quarters of that of women who had acupuncture compared to those who had not had acupuncture.

The delivery analyses also indicated a significant difference between groups after adjustments for the confounding factors. The odds of being the next highest delivery category were only three-quarters as large for women who had acupuncture.

There were significant differences in postnatal length of stay between groups in all analyses. Women who had acupuncture stayed in hospital for 9\% less time than women who hadn't had acupuncture. 


\section{Service feedback data}

The data also took the form of comments, which had a very positive theme throughout. To summarise, pregnant women were grateful for the availability of maternity acupuncture at the Whittington Hospital and many highlighted the acupuncture service as one of the best parts of the maternity care they received. A surprising result was that the positive experience of this service will make them think more carefully about their future choice of hospital.

Together with the quantitative data, there is evidence to suggest that the acupuncture service enhances the patient journey for maternity service users (Table 4).

\section{Discussion}

This observational routine data suggests that birth preparation acupuncture in the third trimester may help to normalise birth by increasing the normal birth rate, reducing the requirement for additional pain relief and reducing the number of steps required in the induction of labour process. It seems that the women accessing this service are older, more nulliparous and more affluent, hence the adjustment for these potential confounders. Women whose labour is induced may have a reduced chance of normal delivery compared with women who go into spontaneous labour (Zhao et al. 2017) - this is why the analysis of mode of delivery is adjusted for induction of labour in addition to the aforementioned potential confounders. Another possible confounder is that women who had acupuncture would have had some degree of continuity of care by the acupuncture team in their third trimester. This study has the flaws of all observational data, such as data entry error into the database and not being able to adjust for other unknown confounders, but we have adjusted for the main known factors. Similarly, the limitations of analysing routine hospital dataset data include unknown confounders, 
limitation of data coding and access to hospital datasets. Furthermore, large organisations such as the Health Technologies Assessment Unit, UK (Raftery et al. 2005) or the Royal College of Obstetricians \& Gynaecologist ${ }^{2}$ (Royal College of Obstetricians and Gynaecologists 2019) do use routine hospital data for assessing trends and identifying areas worthy of further study with better experimental methods.

Our findings have identified that acupuncture may improve physiological birth rates so point to the need better experimental epidemiological studies such as a randomised controlled trial (RCT) or prospective cohort study. However, it should be noted that there is a debate regarding complex interventions and the appropriateness of RCT design for acupuncture research. Smith et al. say 'exploring new research methods, especially those which explore the woman's experience with acupuncture, are also key to defining a role in the future'. (Smith \& Dahlen 2009)

Approximate costs of birth based on the Health Resource Group HRG (NHS Improvement, 2017), for patients with a complication and comorbidity score of 0 are: normal birth is $£ 1,808$; Assisted Delivery with Epidural or Induction is $£ 2,753$; and emergency caesarean is $£ 4,300$. There is some evidence that maternity acupuncture is a cost-effective intervention for pelvic pain (Butel et al. 2016). Acupuncture may be a safe, cost effective as an intervention due to its potential to improve physiological birth rates whist also improving women's experience of pregnancy and childbirth. Any further evaluation of this area should include a health economic analysis.

\section{Conclusion}


We feel that the data that we have presented should be viewed with understanding of the flaws of routine data but also that it points to clinical and physiological areas that could be further evaluated in research designs that are less vulnerable to error and bias, such as prospective studies. Potentiating physiological birth with birth preparation acupuncture in the third trimester may lead to cost savings and improve patient experience of childbirth.

Acknowledgements:

Many thanks to Dr Kate Pateman for data interpretation and Lorena Molossi for data collection.

Declaration of interests:

$\mathrm{AL}$ is on the Board of Directors of the International MotherBaby Childbirth organisation and a Trustee for the Birthlight Charitable Trust. She is a company director of a small publishing company called Docamali Ltd.

VAIE, DP, TA and SK have no declarations of interest.

\section{References}

Birthplace in England Collaborative Group, 2011. Perinatal and maternal outcomes by planned place of birth for healthy women with low risk pregnancies: the Birthplace in England national prospective cohort study. BMJ, 116(9), pp.11771184.

Butel, T. et al. 2016. Cost-Effectiveness of Acupuncture Versus Standard Care for Pelvic and Low Back Pain in Pregnancy: An Analysis of the Game Randomised Trial. Value in Health, 19(7), pp.A588-A589.

Chang, S.B. et al., 2004. [Differences of cesarean section rates according to San-YinJiao(SP6) acupressure for women in labor.]. Taehan Kanho Hakhoe Chi, 34(2), pp.324-332.

de Jonge, A., Geerts, C.C., van der Goes, B.Y., Mol, B.W., Buitendijk, S.E., Nijhuis, J.G., 2015. Perinatal mortality and morbidity up to 28 days after birth among 743070 low-risk planned home and hospital births: a cohort study based on 
three merged national perinatal databases. BJOG, 122(5):720-8. doi: 10.1111/1471-0528.13084..

Dominguez-Bello, M.G., De Jesus-Laboy, K. M., Shen, N., Cox, L. M., Amir, A., Gonzalez, A., Song S. J., Hoashi M., Rivera-Vinas J. I., Mendez K., Knight R., Clemente, J. C., 2016. Partial restoration of the microbiota of cesarean-born infants via vaginal microbial transfer. Nat Med, 22(3), 250-253. doi:10.1038/nm.4039

Duke, K. \& Don, M., 2005. Acupuncture use for pre-birth treatment - A literature review and audit-based research. Complementary Therapies in Clinical Practice, 11(2), pp.121-126.

Einarsdóttir, K. et al., 2013. Role of public and private funding in the rising caesarean section rate: a cohort study. BMJ open, 3(5), pp.1-8. Available at: http://www.pubmedcentral.nih.gov/articlerender.fcgi?artid=3646173 [Accessed January 30, 2018]

Ghui, R. et al., 2016 An evaluation of the guidelines of the Society of Obstetricians and Gynaecologists of Canada, Journal of Obstetrics and Gynaecology. Informa UK Limited, 36(5), pp. 658-662. doi: 10.3109/01443615.2015.1110121.

Gould, A. \& MacPherson, H., 2001. Patient Perspectives on Outcomes After Treatment with Acupuncture. The Journal of Alternative and Complementary Medicine, 7(3), pp.261-268. Available at: http://www.liebertonline.com/doi/abs/10.1089/107555301300328133 [Accessed January 30, 2018].

Gribel, G.P.C., Coca-Velarde, L.G. \& Moreira De Sá, R.A., 2011. Electroacupuncture for cervical ripening prior to labor induction: A randomized clinical trial. Archives of Gynecology and Obstetrics, 283(6), pp.1233-1238.

Higgins, M.F. et al., 2013. Real increasing incidence of hysterectomy for placenta accreta following previous caesarean section. European Journal of Obstetrics Gynecology and Reproductive Biology, 171(1), pp.54-56.

Hodnett, E.D. et al., 2013. Continuous Support for women during chidlbirth. The Cochrane Database of Systematic Reviews, (3), p.CD003766. Available at: http://www.ncbi.nlm.nih.gov/pubmed/17636733. 
Li, X., Hu, J., Wang, X., Zhang, H., \& Liu, J. (2009). Moxibustion and other acupuncture point stimulation methods to treat breech presentation: a systematic review of clinical trials. Chinese Medicine, 4(1), 4. doi:10.1186/1749-8546-4-4

Liddle, S.D. \& Pennick, V., 2015. Interventions for preventing and treating low-back and pelvic pain during pregnancy. The Cochrane database of systematic reviews, (9), p.CD001139. Available at: http://www.ncbi.nlm.nih.gov/pubmed/26422811 [Accessed December 8, 2016].

Lokugamage, A., 2013. In pursuit of the benefits of physiological birth. Midwifery today with international midwife, (108), pp.38-41. Available at: https://www.ncbi.nlm.nih.gov/pubmed/24511839.

Lokugamage, A. (2016). A psycho-biological revival of the 'three Ps' in an integrated antenatal education model. International Journal of Birth and Parent Education. (3) .pp. 5-7.

Mesquita, D.N. et al., 2013. Cesarean Section Is Associated with Increased Peripheral and Central Adiposity in Young Adulthood: Cohort Study. PLoS One, 8(6), p.e66827. Available at: http://www.ncbi.nlm.nih.gov/pubmed/23826150.

Moon, H-Y, Kim, M-r, Hwang, D-S, Jang, J-B, Lee, J, Shin, J-S, Ha, I, Lee, YJ. 2019. Safety of acupuncture during pregnancy: a retrospective cohort study in Korea. BJOG. https://doi.org/10.1111/1471-0528.15925.

Mucuk, S. \& Baser, M., 2014. Effects of noninvasive electroacupuncture on labour pain and duration. Journal of Clinical Nursing, 23(11-12), pp.1603-1610.

Murphy, D.J., 2017. Obstetrics By Ten Teachers 20th Edition., Boca Raton : CRC Press.

NHS Improvement 2017. Reference costs Available at: https://improvement.nhs.uk/resources/reference-costs/ [Accessed December 12, 2017].

Ormsby, S.M., Dahlen, H.G. \& Smith, C.A., 2017. Women's experiences of having depression during pregnancy and receiving acupuncture treatment-A qualitative study. Women and birth : journal of the Australian College of Midwives, 0(0). Available at: http://www.ncbi.nlm.nih.gov/pubmed/29153273 [Accessed January 30, 2018].

Plummer, J.P., 1981. Acupuncture and homeostasis: physiological, physical (postural) and psychological. The American journal of Chinese medicine, 9(1), pp.1-14. 
Prusova, K. et al., 2014. Royal College of Obstetricians and Gynaecologists guidelines: how evidence-based are they? Journal of obstetrics and gynaecology : the journal of the Institute of Obstetrics and Gynaecology, 34(8), pp.706-11. Available at: http://www.ncbi.nlm.nih.gov/pubmed/24922406 [Accessed January 31, 2018].

Rabl, M. et al., 2001. Acupuncture for cervical ripening and induction of labor at term-a randomized controlled trial. Wiener klinische Wochenschrift, 113(23-24), pp.942-6. Available at: http://www.ncbi.nlm.nih.gov/pubmed/11802511 [Accessed January 31, 2018].

Raftery J, Roderick P, Stevens A. Potential use of routine databases in health technology assessment. Health Technol Assess (Rockv). 2005;9(20). doi: $10.3310 /$ hta9200

Royal College of Obstetricians and Gynaecologists. Routine data collection and data monitoring. https://www.rcog.org.uk/en/careers-training/workplace-workforceissues/improving-workplace-behaviours-dealing-withundermining/undermining-toolkit/strategic-interventions/routine-data-collectionand-data-monitoring/. Accessed July 28, 2019.

Smith, C.A. et al., 2017. Acupuncture or acupressure for induction of labour. Cochrane Database of Systematic Reviews, 10(10), p.CD002962. Available at: http://doi.wiley.com/10.1002/14651858.CD002962.pub4 [Accessed January 30, 2018].

Smith, C.A. et al., 2011. Acupuncture or acupressure for pain management in labour (Review). Cochrane Database Syst, (8), p.CD009232. Available at: http://www.ncbi.nlm.nih.gov/pubmed/21735441.

Smith, C. \& Dahlen, H., 2009. Caring for the pregnant woman and her baby in a changing maternity service environment: the role of acupuncture. Acupuncture in Medicine , 27(3), pp.123-125. Available at: http://aim.bmj.com/content/27/3/123.abstract.

Solheim, K.N. et al., 2011. The effect of cesarean delivery rates on the future incidence of placenta previa, placenta accreta, and maternal mortality. Journal of MaternalFetal and Neonatal Medicine, 24(11), pp.1341-1346.

Takeshige, C. et al., 1992. Descending pain inhibitory system involved in acupuncture analgesia. Brain Research Bulletin, 29(5), pp.617-634. Available at: 
https://www.sciencedirect.com/science/article/pii/036192309290131G?via\%3Di hub [Accessed January 30, 2018].

Taylor, S.E. et al., 2000. Biobehavioral responses to stress in females: tend-andbefriend, not fight-or-flight. Psychological review, 107(3), pp.411-429.

Uvnäs-Moberg, K. et al., 1993. The antinociceptive effect of non-noxious sensory stimulation is mediated partly through oxytocinergic mechanisms. Acta physiologica Scandinavica, 149, pp.199-204.

Van den Berg, I., Bosch, J. L., Jacobs, B., Bouman, I., Duvekot, J. J., \& Hunink, M. G. (2008). Effectiveness of acupuncture-type interventions versus expectant management to correct breech presentation: a systematic review. Complement Ther Med, 16(2), 92-100. doi:10.1016/j.ctim.2008.01.001

Vogel, J.P. et al., 2015. Use of the Robson classification to assess caesarean section trends in 21 countries: a secondary analysis of two WHO multicountry surveys. The Lancet Global Health, 3(5), pp.e260-e270. Available at: http://www.ncbi.nlm.nih.gov/pubmed/25866355 [Accessed January 31, 2018].

Watanabe, M. et al., 2014. 03-2 The physical stimulations promote the resilience and the homeostasis of our body and two mechanisms of them. The Journal of The Japanese Society of Balneology, Climatology and Physical Medicine, 77(5), pp.432-432. Available at: https://www.jstage.jst.go.jp/article/onki/77/5/77_432/_article [Accessed January 30, 2018].

Wright, J.D., Pawar, N., Gonzalez, J.S., Lewin, S.N., Burke W.M., Simpson, L.L. et al. (2011) Scientific evidence underlying the American College of Obstetrics and Gynecologists' practice bulletins. Obstetrics and Gynecology 118:505-512.

Zhang, R. et al., 2012. Transcutaneous electrical acupoint stimulation in children with autism and its impact on plasma levels of arginine-vasopressin and oxytocin: A prospective single-blinded controlled study. Research in Developmental Disabilities, 33(4), pp.1136-1146.

Zhao, Y., Flatley, C. \& Kumar, S., 2017. Intrapartum intervention rates and perinatal outcomes following induction of labour compared to expectant management at term from an Australian perinatal centre. Australian and New Zealand Journal of Obstetrics and Gynaecology, 57(1), pp.40-48. Available at: http://doi.wiley.com/10.1111/ajo.12576 [Accessed January 31, 2018]. 
Zhao, Z.-Q., 2008. Neural mechanism underlying acupuncture analgesia. Progress in Neurobiology, 85(4), pp.355-375. Available at: http://linkinghub.elsevier.com/retrieve/pii/S0301008208000579 [Accessed January 30, 2018]. 
Table 1 Acupuncture role in 'Power, Passage and the Passenger'

\begin{tabular}{|c|c|c|}
\hline $\begin{array}{l}\text { Aspect of } \\
\text { Childbirth }\end{array}$ & Evidence & Reference \\
\hline \multirow[t]{2}{*}{ Power } & $\begin{array}{l}\text { Empowerment of } \\
\text { women by } \\
\text { reduction of } \\
\text { anxiety in } \\
\text { childbirth }\end{array}$ & $\begin{array}{l}\text { Hodnett ED, Gates S, Hofmeyr GJ, Sakala C. } \\
\text { Continuous support for women during childbirth. } \\
\text { Cochrane Database Syst Rev 2013; } \\
\text { 7:CD003766. } \\
\text { Lokugamage A. In pursuit of the benefits of } \\
\text { physiological birth. Midwifery Today Int Midwife } \\
\text { 2013;(108):38-41. } \\
\text { Taylor SE, Klein LC, Lewis BP, Gruenewald TL, } \\
\text { Gurung RA, Updegraff JA. Biobehavioral } \\
\text { responses to stress in females: tend-and- } \\
\text { befriend, not fight-or-flight. Psychol Rev } 2000 \text {; } \\
\text { 107(3):411-429. }\end{array}$ \\
\hline & $\begin{array}{l}\text { Contributes } \\
\text { towards release } \\
\text { of oxytocin }\end{array}$ & $\begin{array}{l}\text { Uvnäs-Moberg K, Bruzelius G, Alster P, } \\
\text { Lundeberg T. The antinociceptive effect of non- } \\
\text { noxious sensory stimulation is mediated partly } \\
\text { through oxytocinergic mechanisms. Acta } \\
\text { Physiol Scand 1993; 149(2):199-204. } \\
\text { Zhang R, Jia MX, Zhang JS, Xu XJ, Shou XJ, } \\
\text { Zhang XT et al. Transcutaneous electrical } \\
\text { acupoint stimulation in children with autism and }\end{array}$ \\
\hline
\end{tabular}




\begin{tabular}{|c|c|c|}
\hline & & $\begin{array}{l}\text { its impact on plasma levels of arginine- } \\
\text { vasopressin and oxytocin: a prospective single- } \\
\text { blinded controlled study. Res Dev Disabil 2012; } \\
33(4): 1136-1146 .\end{array}$ \\
\hline \multirow[t]{4}{*}{ Passage } & $\begin{array}{l}\text { Beneficial in } \\
\text { pelvic / back pain } \\
\text { of pregnancy }\end{array}$ & $\begin{array}{l}\text { Liddle, S.D. \& Pennick, V., 2015. Interventions } \\
\text { for preventing and treating low-back and pelvic } \\
\text { pain during pregnancy. The Cochrane database } \\
\text { of systematic reviews, (9), p.CD001139. }\end{array}$ \\
\hline & $\begin{array}{l}\text { Use as a labour } \\
\text { analgesia }\end{array}$ & $\begin{array}{l}\text { Smith, C.A. et al., 2011. Acupuncture or } \\
\text { acupressure for pain management in labour } \\
\text { (Review). Cochrane Database Syst, (8), } \\
\text { p.CD009232. }\end{array}$ \\
\hline & $\begin{array}{l}\text { Reduction of the } \\
\text { length of labour }\end{array}$ & $\begin{array}{l}\text { Mucuk S, Baser M. Effects of noninvasive } \\
\text { electroacupuncture on labour pain and duration. } \\
\text { J Clin Nurs 2014; 23(11-12):1603-1610. }\end{array}$ \\
\hline & $\begin{array}{l}\text { Promotion of } \\
\text { cervical ripening }\end{array}$ & $\begin{array}{l}\text { Smith, C.A. et al., 2017. Acupuncture or } \\
\text { acupressure for induction of labour. Cochrane } \\
\text { Database of Systematic Reviews, 10(10), } \\
\text { p.CD002962. } \\
\text { Gribel, G.P.C., Coca-Velarde, L.G. \& Moreira } \\
\text { De Sá, R.A., 2011. Electroacupuncture for } \\
\text { cervical ripening prior to labor induction: A }\end{array}$ \\
\hline
\end{tabular}




\begin{tabular}{|c|c|c|}
\hline & & $\begin{array}{l}\text { randomized clinical trial. Archives of } \\
\text { Gynecology and Obstetrics, 283(6), pp.1233- } \\
1238 . \\
\text { Rabl, M. et al., 2001. Acupuncture for cervical } \\
\text { ripening and induction of labor at term--a } \\
\text { randomized controlled trial. Wiener klinische } \\
\text { Wochenschrift, 113(23-24), pp.942-6. }\end{array}$ \\
\hline Passenger & $\begin{array}{l}\text { Resolving breech } \\
\text { position of foetus } \\
\text { to reduce } \\
\text { caesarean births }\end{array}$ & $\begin{array}{l}\text { Li, X., Hu, J., Wang, X., Zhang, H., \& Liu, J. } \\
\text { (2009). Moxibustion and other acupuncture } \\
\text { point stimulation methods to treat breech } \\
\text { presentation: a systematic review of clinical } \\
\text { trials. Chinese Medicine, 4(1), } 4 . \\
\text { Van den Berg, I., Bosch, J. L., Jacobs, B., } \\
\text { Bouman, I., Duvekot, J. J., \& Hunink, M. G. } \\
\text { (2008). Effectiveness of acupuncture-type } \\
\text { interventions versus expectant management to } \\
\text { correct breech presentation: a systematic } \\
\text { review. Complement Ther Med, 16(2), 92-100. }\end{array}$ \\
\hline
\end{tabular}


Table 2: Demographics

\begin{tabular}{|c|c|c|c|c|}
\hline Variable & Category & $\begin{array}{l}\text { No } \\
\text { Acupuncture } \\
\text { Mean (SD) }\end{array}$ & $\begin{array}{l}\text { Acupuncture } \\
\text { Mean (SD) }\end{array}$ & P-value \\
\hline Age & - & $30.9(6.0)$ & $33.8(4.6)$ & $<0.001$ \\
\hline Variable & Category & $\begin{array}{l}\text { No } \\
\text { Acupuncture } \\
\mathrm{N}(\%)\end{array}$ & $\begin{array}{l}\text { Acupuncture } \\
\mathrm{N}(\%)\end{array}$ & P-value \\
\hline Parity & $\begin{array}{l}0 \\
1 \\
2 \\
3+\end{array}$ & $\begin{array}{l}2763(48 \%) \\
1706(30 \%) \\
668(12 \%) \\
595(10 \%)\end{array}$ & $\begin{array}{l}426(71 \%) \\
148(25 \%) \\
24(4 \%) \\
5(1 \%)\end{array}$ & $<0.001$ \\
\hline Deprivation & $\begin{array}{l}1^{\text {st }} \text { quintile (least } \\
\text { deprived) } \\
2^{\text {nd }} \text { quintile } \\
3^{\text {rd }} \text { quintile } \\
4^{\text {th }} \text { quintile } \\
5^{\text {th }} \text { quintile (most } \\
\text { deprived) }\end{array}$ & $\begin{array}{l}1080(19 \%) \\
1092(19 \%) \\
1147(20 \%) \\
1179(21 \%) \\
1215(22 \%)\end{array}$ & $\begin{array}{l}187(31 \%) \\
160(27 \%) \\
124(21 \%) \\
77(13 \%) \\
5(9 \%)\end{array}$ & $<0.001$ \\
\hline
\end{tabular}


Table 3: Intrapartum and birth outcomes

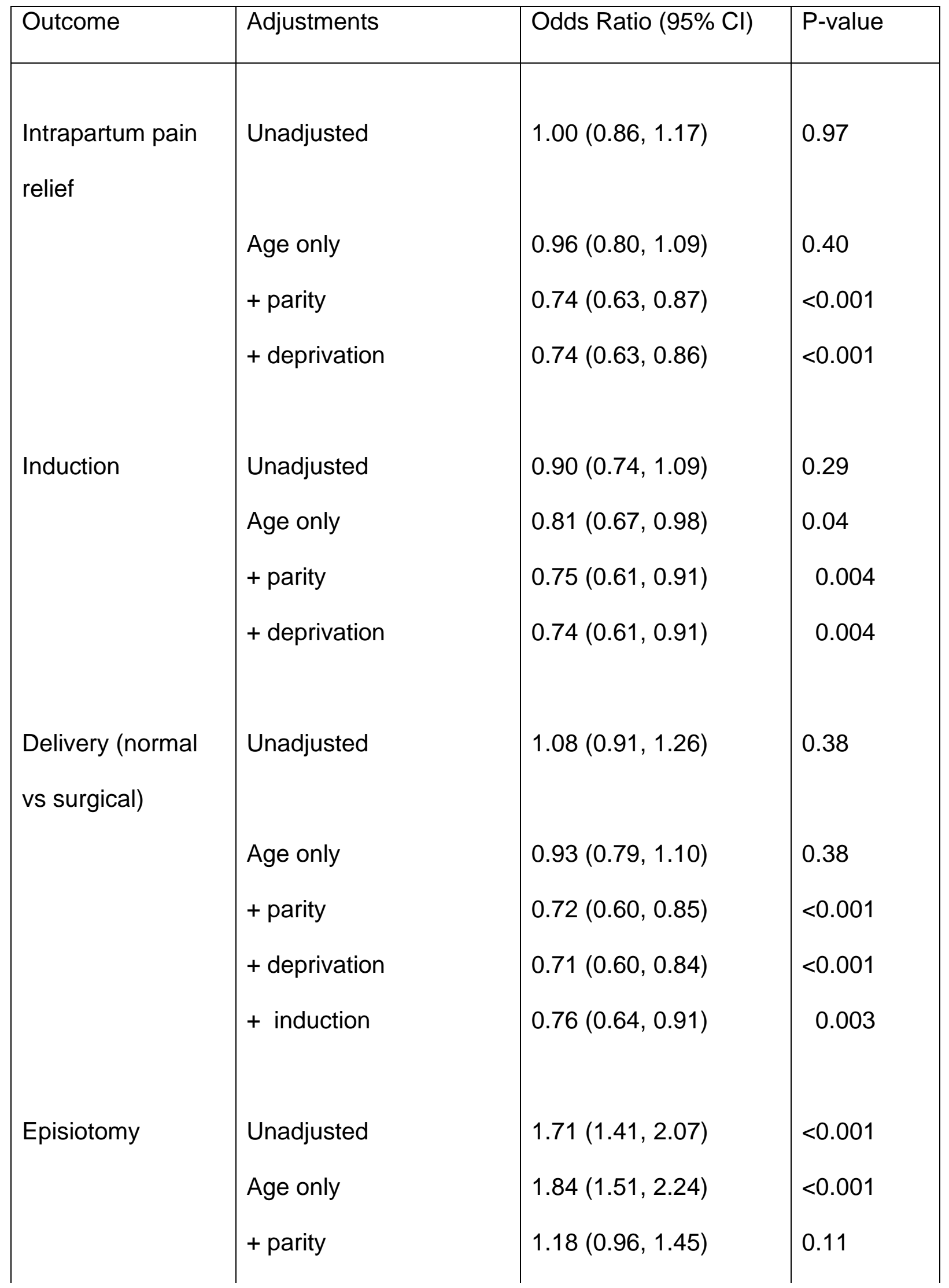




\begin{tabular}{|c|c|c|c|}
\hline & $\begin{array}{l}+ \text { deprivation } \\
+ \text { type of delivery }\end{array}$ & $\begin{array}{l}1.18(0.96,1.45) \\
0.94(0.70,1.26)\end{array}$ & $\begin{array}{l}0.12 \\
0.69\end{array}$ \\
\hline Outcome & Adjustments & Ratio $(95 \% \mathrm{Cl})$ & P-value \\
\hline $\begin{array}{l}\text { Postnatal length } \\
\text { of stay }\end{array}$ & $\begin{array}{l}\text { Unadjusted } \\
\text { Age only } \\
+ \text { parity } \\
+ \text { deprivation } \\
+ \text { type of delivery }\end{array}$ & $\begin{array}{l}0.91(0.87,0.96) \\
0.90(0.86,0.95) \\
0.86(0.82,0.90) \\
0.86(0.82,0.90) \\
0.91(0.87,0.95)\end{array}$ & $\begin{array}{l}<0.001 \\
<0.001 \\
<0.001 \\
<0.001 \\
<0.001\end{array}$ \\
\hline
\end{tabular}


Table 4: Service feedback data

\begin{tabular}{|l|l|l|l|l|}
\hline Question & Response & 2014 & 2015 & 2016 \\
\hline Respondents & & 29 & 22 & 30 \\
\hline $\begin{array}{l}\text { How did you feel } \\
\text { acupuncture affected your }\end{array}$ & $\begin{array}{l}\text { Greatly } \\
\text { benefitted }\end{array}$ & $83 \%$ & $73 \%$ & $77 \%$ \\
\hline $\begin{array}{l}\text { Slightly } \\
\text { benefitted }\end{array}$ & $17 \%$ & $18 \%$ & $23 \%$ \\
\hline service affect your journey & $\begin{array}{l}\text { Made no } \\
\text { difference }\end{array}$ & $0 \%$ & $9 \%$ & $0 \%$ \\
\hline patient experience \\
affect your wellbeing?
\end{tabular}




\begin{tabular}{|l|l|l|l|l|}
\hline $\begin{array}{l}\text { through your pregnancy at } \\
\text { the Whittington? }\end{array}$ & $\begin{array}{l}\text { Made no } \\
\text { difference }\end{array}$ & $3 \%$ & $0 \%$ & $0 \%$ \\
\hline $\begin{array}{l}\text { Negatively } \\
\text { affected }\end{array}$ & $0 \%$ & $0 \%$ & $0 \%$ \\
\hline $\begin{array}{l}\text { mid the availability of } \\
\text { influence your choice of } \\
\text { hospital? }\end{array}$ & Yes & $10 \%$ & $23 \%$ & $30 \%$ \\
\hline $\begin{array}{l}\text { Ycupuncture } \\
\text { future? }\end{array}$ & choice of hospital in the \\
service influence your & Yndifferent & $4 \%$ & $36 \%$ & $47 \%$ \\
\hline No & $86 \%$ & $41 \%$ & $23 \%$ \\
\hline Nould the acupuncture & Yes & $100 \%$ & $95 \%$ & $100 \%$ \\
\hline & $0 \%$ & $5 \%$ & $0 \%$ \\
\hline
\end{tabular}

